\title{
EVALUATION OF OLD CORRUGATED CONTAINER AND WOOD FIBER APPLICATION ON SURFACE ROUGHNESS OF THREE- LAYER PARTICLEBOARD
}

\author{
Hamideh Abdolzadeh ${ }^{*}$ and Kazem Doosthoseini \\ This paper presents the results of a study to use virgin wood and OCC \\ fiber for particleboard production. Three-layer boards, with wood and \\ OCC fiber on the surface, were fabricated. The type of applied furnishes \\ at surface layers, moisture, and adhesive content were considered as \\ variables, and their effects on roughness of manufactured particleboards \\ were examined. The panels were produced with $10 \%$ and $12 \%$ urea \\ formaldehyde (UF) adhesive at $10 \%$ and $14 \%$ moisture content. The \\ surface characteristics were investigated. The results indicated that \\ wood and OCC fiber utilization on the surface layer gave smoother \\ surfaces than a control board with fine wood particles on its surface. The \\ surface roughness decreased as adhesive and moisture content \\ increased.
}

Keywords: Surface Roughness; OCC Fiber; Wood Fiber; Particleboard; Urea formaldehyde

Contact information: Department of Wood and Paper Science \& Technology, Natural Resources Faculty, University of Tehran, P. O. Box 31585, Karaj, Iran; *Corresponding author: h_abdolzadeh@yahoo.com

\section{INTRODUCTION}

Particleboard is a wood-based panel composite manufactured under pressure and temperature from particles of wood or other lignocellulosic materials and a binder. A decrease in the availability of raw material and the need to conserve natural resources has prompted research regarding more efficient use of trees. Many particleboards can utilize low-grade logs such as thinnings, as well as bowed and twisted logs. They produce a lot of residues in the form of chips sawdust and slab. These residues can be used to manufacture some of the many kinds of particleboards. Wood is a very variable material, both between and within species, and not just in appearance but, more importantly in density, strength, and durability. Although the strength properties of particleboard are generally lower than nature lumber, they are more consistent. Other benefits of particleboard come from the fact that its properties can be engineered, and the particleboard can be bought in much larger sizes than lumber (EN 309. 1992; Maloney and Miller 1993; Nemli 2000; Nemli et al. 2005).

Some of the typical applications for particleboard include floor underlayment, housing, cabinets, stair treads, shelving table tops, furniture, vanities, speakers, lock blocks, sliding doors, interior signs, displays, pool tables, electronic game consoles, and table tennis tables (Anonymous 1996). Interior fitment and furniture manufactures are using increasing ratios of decorative surfacing materials for wood-based panels (particleboard and MDF). Both of these panels are manufactured as uniform, flat panels 
that provide excellent surface for the application of coating materials. These coated panels are used in the construction of cabinet, furniture, paneling, kitchen worktops and work surface in offices, educational establishments, laboratories, and other industrial product applications. The purposes of coating of particleboard surface with decorative overlays are the prevention of the absorption of water and humidity, and the elimination of the release of formaldehyde. The performance of the coated panels is dependent on the quality of the wood-based panel and the type of the coating material (Hoag 1993; Vansteenkiste 1981).

Surface roughness of the particleboard is very important for coating with thin overlays such as melamine saturated paper, foils, and thin film. Any surface irregularities on the substrate may show through the overlay films and paper, influencing the quality of the final product. Therefore, it is necessary to increase quality of surface layer. MDF has a smoother surface than that of any other composite panels, such as particleboard. In sandwich panels, wood fibers are used in surface layer, therefore their surface quality is higher than other particleboards. Because of the high cost of wood fiber, the use of old corrugated container (OCC) fiber can be useful and economical.

The height, width, and shape of the irregularities on a surface establish the surface quality of the product. There are several methods to quantify surface roughness of wood composites, such as pneumatic, acoustic, emission, light scattering, laser, and stylus methods (Drew 1992; Hiziroglu 1996; Mitchell and Lemaster 2002; Lemaster and Beal 1993). The stylus method, which is widely used to evaluate metal and plastic surfaces, gains most attention, since it determines the surface quality in term of well established numerical parameters (Stumbo 1963; Suchsland 2004; Hiziroglu et al. 2004). It is accurate, practical, and repeatable, and quantitative roughness parameters can also be precisely calculated by this method. Variables such as the stylus tip radius, the surface force produced by the stylus, and cut-off length of the profile have important influence on the accuracy of the results (ANSI 2002; Hiziroglu and Suchsland 1993; Funck et al, 1992). The cut-off length, which is a filtering parameter, separates the unfiltered actual profile into contributing profiles, namely roughness and waviness profiles. Based on the standard, the cut-off length should be at least 2.5 times the peak-to-peak spacing of the profile roughness, so that a minimum of two speaks and valley can be included within each cut-off length. All roughness parameters, including $\mathrm{R}_{\mathrm{a}}, \mathrm{R}_{\mathrm{z}}, \mathrm{R}_{\mathrm{q}}$, and $\mathrm{R}_{\max }$, are calculated based on the filtered roughness profile.

Surface roughness was investigated by several authors. Hiziroglu and Graham (1998) determined that the particleboards made by using a 45 s press closing time with the same out of press thickness resulted in rougher surfaces than those made by using 36 s press closing time. Nees et al. (2004) stated that several factors affected mechanical processing and in turn affect surface roughness of the wood. Hardwoods have smoother surface than softwoods. Hiziroglu and Suchsland (1993) reported that increasing moisture content of the particleboard caused high surface roughness values. Nemli et al. (2005) evaluated the effects of raw material type, pressure, shelling ratio, and density on the surface characteristics of particleboard. Hiziroglu and Kosonkorn (2006) evaluated surface roughness of Thai medium density fiber board (MDF). 
The objective of this study is evaluation of OCC and wood fiber application on surface roughness of three-layer particleboard for increasing surface quality and optimizing it for thin overlays such as melamine saturated paper, foils, and thin film.

\section{EXPERIMENTAL}

\section{Raw Materials}

OCC and wood fiber from mixed hardwood (beech, hornbeam, and poplar) were provided from Karaj's supermarkets and Babolsar Fiberboard Ltd., respectively. The average moisture contents of OCC, wood fibers, and wood particles were adjusted to $1 \%$ before mat preparation. Urea formaldehyde (UF) with formaldehyde/urea molar ratio of $0.95: 1$ was used as the adhesive at two levels of $10 \%$ and $12 \%$ (oven dry solid wood basis). The characteristics of the adhesive used are summarized in Table 1. Ammonium chloride $\left(\mathrm{NH}_{4} \mathrm{Cl}\right)$ was added as a hardener in the urea-formaldehyde adhesive at a level of $2 \%$ (dry resin basis).

Table 1. Characteristics of the Urea-Formaldehyde Adhesive

\begin{tabular}{cccc}
\hline Density $\left(\mathrm{gr.cm}^{-3}\right)$ & Gel time(s) & $\begin{array}{c}\text { Viscosity (CP) } \\
\text { DIN Cup/ } 4 \mathrm{~mm} / 20^{\circ} \mathrm{C}\end{array}$ & Solid content (\%) \\
\hline 1.26 & 60 & 350 & 63 \\
\hline
\end{tabular}

\section{OCC and Wood Fiber Preparation}

OCC was torn apart in small pieces and pulped in a laboratory pulper under conditions of 5\% consistency and $200 \mathrm{rpm}$ for $30 \mathrm{~min}$. The obtained pulp was then passed through a 20 -mesh screen to remove any fiber bundles. The received virgin wood fibers and OCC fibers were air-dried at first and then dried further in an oven at $100 \pm 3{ }^{\circ} \mathrm{C}$ to reach the moisture content of approximately $1 \%$. The dried fibers were then kept in sealed plastic polyethylene bags prior to mat fabrication.

\section{Mat Fabrication}

The furnish materials for surface layer (wood virgin fiber, OCC fiber and fine wood particles) and for core were used. OCC and wood fiber and wood particles were blended separately with the urea formaldehyde ( $8 \%$ for core and $10 \%$ and $12 \%$ for the face), using a laboratory blender with a rotor speed of $20 \mathrm{rpm}$. The moisture content of furnishes was adjusted at two levels, i.e. $10 \%$ and $14 \%$ for the face, and $10 \%$ for the core. The shelling ratio, the ratio of face thickness to the total thickness of the panels, was 1:2. The mats were formed using a laboratory mold with dimensions of $350 \times 350 \mathrm{~mm}$.

\section{Board Manufacture}

Three types of laminated board were fabricated. They included the particleboards with wood and OCC fiber and fine particles of wood as a control on the surface layer and wood particles in the core (see Fig. 1). The applied press conditions were: pressure of 30 $\mathrm{kg} \mathrm{cm}^{-2}$ at $180{ }^{\circ} \mathrm{C}$ for $5 \mathrm{~min}$. The dimensions of the boards were $350 \times 350 \times 150 \mathrm{~mm}$. All of the boards were manufactured with an average target density of $0.75 \mathrm{~g} \mathrm{~cm}^{-3}$. Three 
replicate sample boards were fabricated for each treatment. The boards were conditioned at $65 \pm 1 \%$ relative humidity and $20 \pm 3^{\circ} \mathrm{C}$ for about 3 weeks before being cut into test specimens.

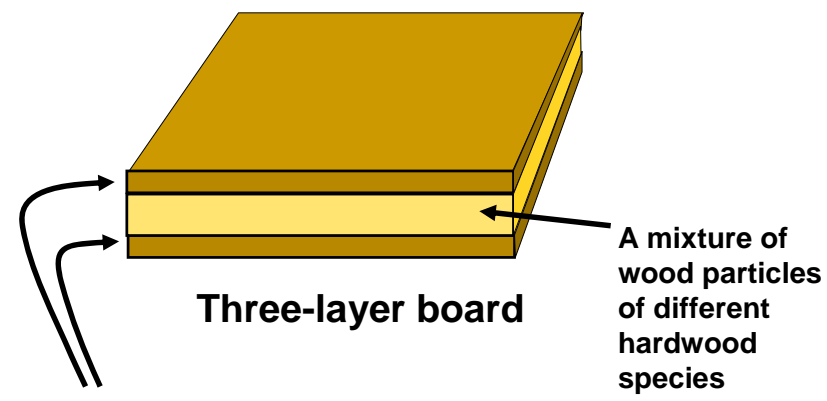

Fine wood particle and OCC and wood fiber in the surface layer

Fig. 1. The Schematic design of distribution of the furnish materials for surface and core layers in three-layer boards.

\section{Roughness Measurement}

The boards were cut into test specimens according to the DIN 68763 standard. Three specimens were prepared from each sample board to determine the surface roughness. A Mitutoyo Surftest SJ-201 instrument (Fig.2.) was employed for the surface roughness measurement. The $R_{a}$ (average roughness), $R_{z}$ (mean peak-to-valley height), and $\mathrm{R}_{\mathrm{q}}$ (root mean square roughness value) roughness parameters were measured to evaluate surface roughness of the samples according to the DIN 4768 (1990) standard. The cut-off length $(\lambda \mathrm{c})$ and tracing length were $2.5 \mathrm{~mm}$ and $12.5 \mathrm{~mm}$, respectively. The pick-up had a skid type diamond stylus with a radius of $5 \mu \mathrm{m}$ and a tip angle of 90.

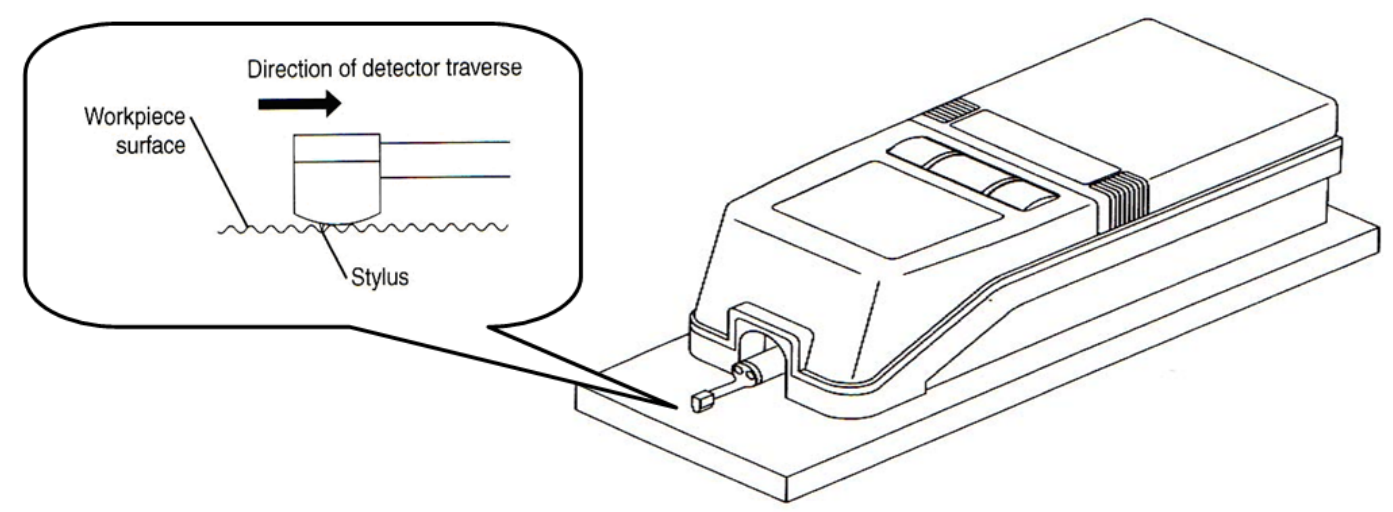

Fig. 2. Schematic design from Mitutoyo surftest SJ 201 instrument and detector stylus

\section{Statistical Analysis}

The data were analyzed using analysis of variance; comparison of the means was carried out employing the Duncan test, with a 95\% confidence level. 


\section{RESULTS AND DISCUSSION}

Surface roughness values of panels with wood virgin fiber, OCC fiber, and control specimens with wood particles on the surface layers were significantly different. Results of the variance analysis also indicated a significant difference between $R_{a}, R_{z}$, and $R_{q}$ values of all panels. Mean values of $R_{a}, R_{z}$, and $R_{q}$ are found in Table 2 . The board samples with OCC and wood fibers had lower surface roughness values than panels manufactured with the wood particles in surface layer, as can be seen in Fig. 3. The panels with OCC fiber in the surface layer showed the surface roughness values between the panel with wood fiber and wood particles as a control.

Table 2. Surface Roughness Values $\left(R_{a}, R_{z}\right.$, and $\left.R_{q}\right)$ of Laminated Boards

\begin{tabular}{lccccccc}
\hline Control & $\begin{array}{c}\text { OCC } \\
\text { Fiber }\end{array}$ & $\begin{array}{c}\text { Wood } \\
\text { Fiber }\end{array}$ & $\begin{array}{c}\mathrm{MC}_{1} \\
(10 \%)\end{array}$ & $\begin{array}{c}\mathrm{MC}_{2} \\
(14 \%)\end{array}$ & $\begin{array}{c}\text { Resin } \\
\text { content } \\
(10 \%)\end{array}$ & $\begin{array}{c}\text { Resin } \\
\text { content } \\
(12 \%)\end{array}$ \\
\hline $\mathrm{R}_{\mathrm{a}}(\mu \mathrm{m})$ & 25.178 & 14.631 & 12.587 & 18.582 & 16.582 & 18.804 & 16.126 \\
$\mathrm{R}_{\mathrm{z}}(\mu \mathrm{m})$ & 154.03 & 100.658 & 86.037 & 122.417 & 104.729 & 119.049 & 108.097 \\
$\mathrm{R}_{\mathrm{q}}(\mu \mathrm{m})$ & 32.347 & 18.693 & 15.259 & 23.643 & 20.557 & 23.457 & 20.745 \\
\hline
\end{tabular}

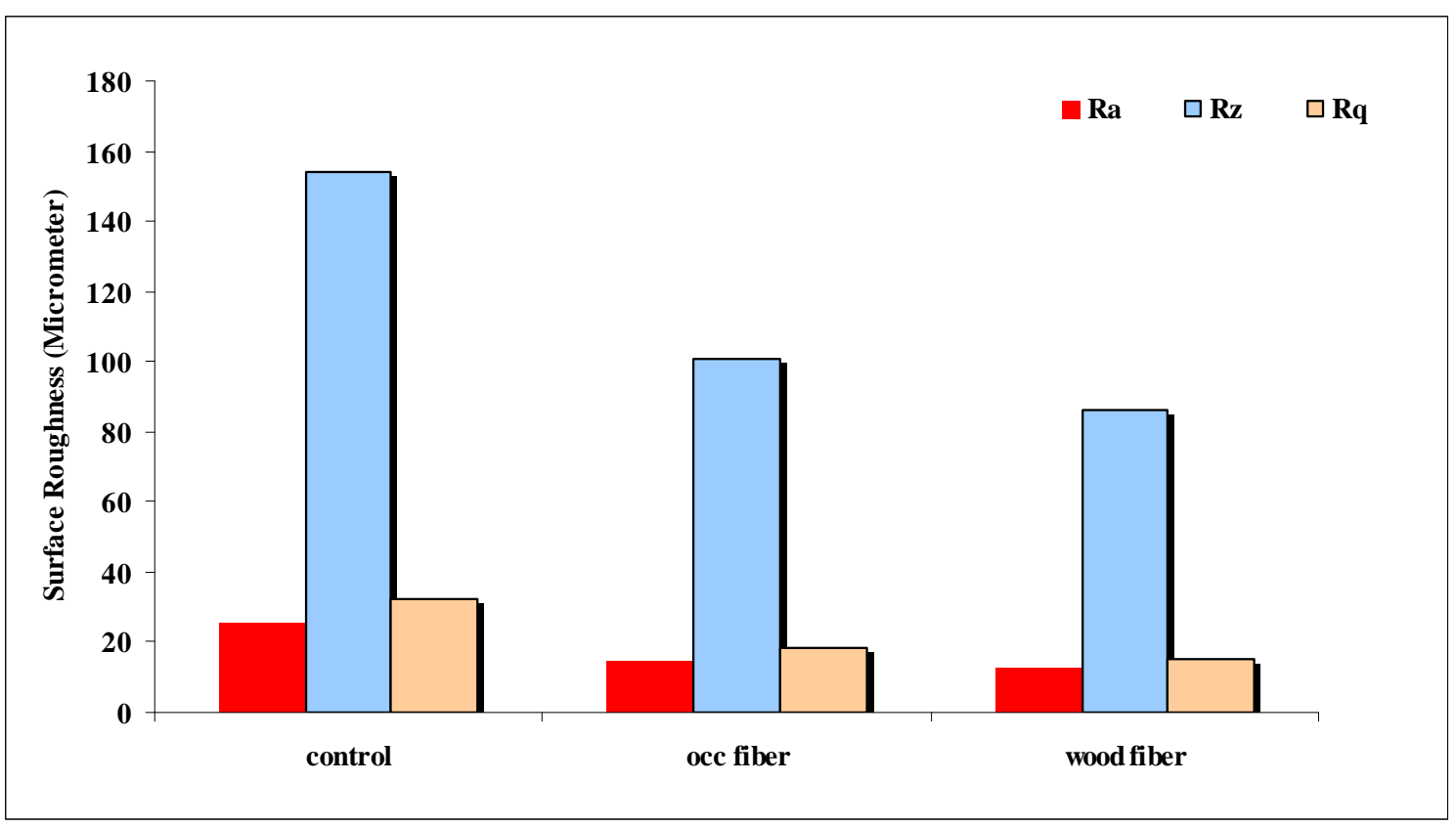

Fig. 3. Effect of utilization of wood and OCC fiber on surface roughness of the three-layer boards

However, on the basis of the Duncan's mean separation test, panels with wood and OCC fiber were within the same group. In other words, there was no significant difference between surface roughnesses with wood fibers vs. OCC fibers in the surface layer. Wood and OCC fiber, on the surface, can be pressed more easily than wood particles, as in the control samples. Application of fibers in the surface layers of the boards resulted in the formation of a compact and tight structure with low porosity on the surfaces. In addition, fiber utilization in outer layers increased the density of particle boards, because of greater compression during the hot pressing. For these reasons, 
utilization of OCC and wood virgin fiber in surface layer resulted in better surface characteristics. Even if very fine wood particles are used on the face layer of the particleboard, pits and peaks due to larger geometry of particles than fibers resulted in rougher surface characteristics (Hiziroglu 1996; Wechsler and Hiziroglu 2007).

The influence of moisture content on the roughness of three-layer particleboard is presented in Fig. 4. The surfaces of the panels at 10\% mat moisture content (MC) were found to be rougher than those of the boards at $14 \%$ mat moisture content. When surface layer mat moisture content was increased, its density was increased concurrently. This is due to low porosity resulting in high density, as well as a more compact and tighter structure of the particleboard at high moisture content in surface layer compared to the lower moisture content on laminated boards (Kalaycioglu et al. 2005; Kalaycioglua, and Hiziroglu 2006; Nemli et al. 2007; Ozdemir et al. 2009). The relatively high flexibility of wood fiber in the board produced at $14 \%$ moisture content may cause these results. The same results were also found in studies conducted by Siemensky and Skarzynska (1998) and Nemli (2005).

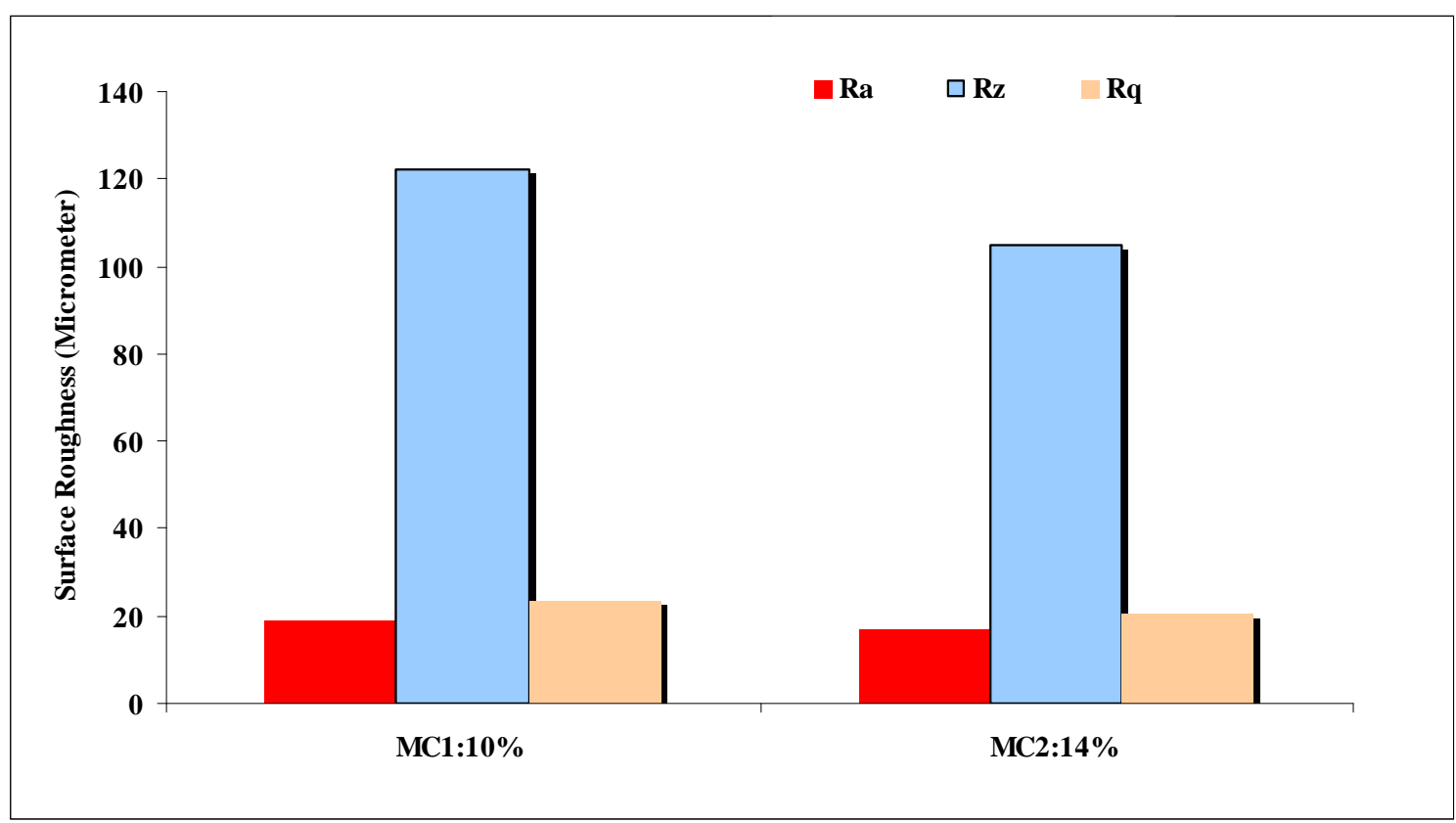

Fig. 4. Effect of moisture content (MC) of mat on surface roughness of the three layer boards

The influence of the resin content on the roughness of laminated particleboard is presented in Fig. 5. Panels with higher resin content had smoother surfaces than those with lower resin content. As can be seen from the figure, the particleboards with $12 \%$ resin content on the surface layer did have smoother surface than those with $10 \%$ resin content. The mean values of $R_{a}, R_{z}$, and $R_{q}$ for the panels with higher resin content on the face layers were determined as 16.10, 108.10, and 20.75, respectively, due to more densification of the face layers. These results are consistent with the findings of other researchers (Aydin et al. 2006; Hiziroglu, and Suzuki 2007; Hiziroglu, and Holcomb 2005; Nemli et al.2007). 


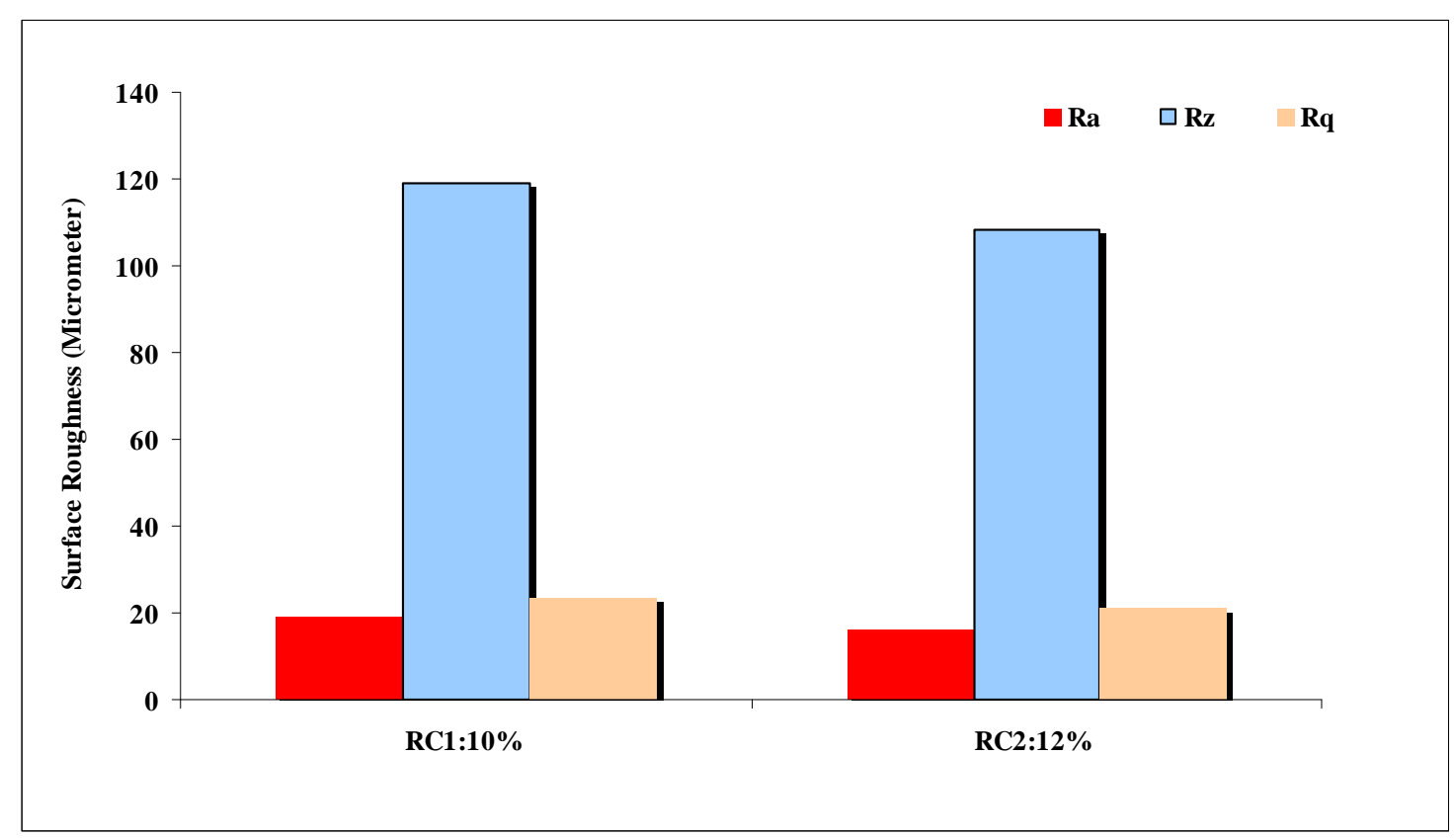

Fig. 5. Effect of resin content (RC) of mat on surface roughness of the three-layer boards

\section{CONCLUSIONS}

In this study, surface roughness of the three-layer particleboards was determined by using a contact stylus method, and the following conclusions can be made:

1. The type of surface material has an important effect on surface roughness of laminated particleboard. Surface stability test suggests that the board with wood and OCC fiber in the surface had smoother surfaces than control samples.

2. Particleboard samples with $12 \%$ resin content in the surface layer exhibited better surface characteristics than panels with $10 \%$ resin content. Increasing resin content in surface layer decreased the surface roughness of the particleboard.

3. Mat moisture content of surface layer was found to affect the surface roughness. Particleboard with 14\% mat moisture content in the surface layer during manufacture exhibited better surface characteristics than panels with $10 \%$ moisture content.

4. This study showed that the type of material in the surface layer, moisture content, and resin content were some manufacturing parameters affecting the surface quality of the particleboard.

5. Additional work is needed to determine the effects of other manufacturing parameters such as layer number, particle geometry, adhesive type and amount, press temperature, and time on the surface roughness of particleboard.

6. Also determining density profiles and any other mechanical and physical parameters could give detail information about surface quality of samples as function of treatment. 


\section{ACKNOWLEDGMENTS}

The authors would like to thank Dr. M. Azadfallah for helping to adjust this paper and useful advices.

\section{REFERENCES CITED}

Anonymous. (1996). "Particleboard-from start to finish," National Particleboard Association, Gaithersburg.

ANSI. (2002). "Surface texture: Surface roughness, waviness and lay," B46.1 (Revision ANSI/ASME B46.1 2002)," New York: The American Society of Mechanical Engineers.

Aydin, I., Colakoglu, G., and Hiziroglu, S. (2006). "Surface characteristics of spruce veneer and shear strength of plywood as a function of log temperature in peeling process," Int. J. of Solid and Struct. 43, 6140-6147.

Drew, W. E. (1992). "Surface texture measurement errors: Stylus type instruments," Quality. October, 41-44.

EN 309. (1992). "Wood particleboards-definition and classification," European Committee Standardization, Brussels.

Funck, J. W., Forrerr, J. B., Brutler, C. C., and Maristany, A. G. (1992). "Measuring surface roughness of wood: A comparison of laser scatter and stylus tracing approaches," In: Proceedings of the Society of Photo-Optical Instrumentation Engineers, Vol. 1821, Bellingham, Washington, p. 173-183.

Geimer, R. L. (1979). "Basic data to the engineering design of reconstituted flake board," In: Proceedings of the Washington State University Symposium on Particleboard, Washington: Pullman; p. 104-25.

Hiziroglu, S., and Suchsland, O. (1993). "Linear expansion and surface stability of particleboard," For. Prod. J. 43(4), 31-34.

Hiziroglu, S. (1996). "Surface roughness analysis of wood composites: A stylus method," For. Prod. J. 46(7/8), 67-72.

Hiziroglu, S., and Graham, M. (1998). "Effect of press closing time and target thickness on surface roughness of particleboard," For. Prod. J. 48(3), 50-54.

Hiziroglu, S., Jarusombuti, S., and Fuengvivat, V. (2004). "Surface characteristics of wood composites manufactured in Thailand," J. Build. and Environ. 39, 1359-1364.

Hiziroglu, S., and Kosonkorn, P. (2006). "Evaluation of surface roughness of Thai medium density fiberboard (MDF)," J. Build. and Environ. 41, 527-533.

Hiziroglu, S., and Suzuki, S. (2007). "Short technical note: Evaluation of surface roughness of commercially manufactured particleboard and medium density fiberboard in Japan," J. of Mater. Process Technol. 184, 436-440.

Hiziroglu, S., and Holcomb, R. (2005). "Some of the properties of three-layer particleboard made from eastern red cedar," J. Build. and Environ. 40, 719-723.

Hoag, M. (1993). "Particleboard and medium density fiberboard: Surface-testing substrates for laminating application," Eur. Plast. Laminates Forum, Koln, Gremany. P 33-40. 
Hoffstrand, A. D., Moslemi, A. A., and Garcia, J. F. (1984). "Curing characteristics of wood particles from nine northern rocky mountains species mixed with Portland cement," For. Prod. J. 4(7), 5761.

Kalaycioglu, H., Deniz, I., and Hiziroglu, S. (2005). "Some of the properties of particleboard made from paulownia," J. Wood. Sci. 51, 410-414.

Kalaycioglu, H., and Hiziroglu, S. (2006) "Evaluation of surface characteristics of laminated flooring," J. Build. and Environ. 41, 756-762

Lemaster, R. L., and Beal, F. C. (1993). "The use of dual sensors to measure surface roughness of wood-based composites," In: Proceedings of the Ninth Internation Symposium on Non-Destructive Testing of Wood, Forest Products Society, Madison, Wisconsin, 123-130.

Maloney, T. (1993). Modern Particleboard and Dry-Process Fiberboard Manufacturing, Miller Freeman Publishing Inc., San Francisco, CA.

Mitchell, P., and Lemaster, R. (2002). "Investigation of machine parameters on the surface quality in routing soft maple," For. Prod. J. 52(6) 85-90.

Mummery, L. (1991). Surface Texture Analysis. The Handbook, Muhlhausen, Germany, Hommelwerke, 106 pp.

Nees, J. L., Reeb, J. E., and Funck, J. W. (2004). "Traditional surface roughness measures to glue-bond quality in plywood," For. Prod. J. 54(1), 67-73.

Nemli, G. (2000). "Effect of coating materials process parameters on the technological properties of particleboard," $\mathrm{PhD}$ dissertation, Karadeniz Technical University, Trabzon, Turkey; [in Turkish].

Nemli, G., Ozturk, I., and Aydin, I. (2005). "Some of the parameters influencing surface roughness of particleboard," J. of Build. Environ. 40, 1337-1340.

Nemli, G., Aydın, I., and Zekovic, E. (2007). "Evaluation of some of the properties of particleboard as function of manufacturing parameters," Mater. and Des. 28, 11691176.

Ozdemir, T., Hiziroglu, S., Malkocoglu, A. (2009) "Influence of relative humidity on surface quality and adhesion strength of coated medium density fiberboard (MDF) panels," Materials and Design 30, 2543-2546.

Stumbo, D. A. (1963). "Surface texture, measuring methods," For. Prod. J. 12(7), 299303.

Suchsland, O. (2004). The Swelling and Shrinkage of Wood, Wisconsin, Madison: Forest Products Society.

Vansteenkiste, R. (1981). "Surface treatment of wood based panels," Seminar on Wood Based Panels and Furniture Industries, Beijing.

Wechsler, A., and Hiziroglu, S. (2007). "Some of the properties of wood-plastic composites," J. Build. and Environ. 42, 2637-2644.

Article submitted: April 28, 2009; Peer review completed: May 23, 2009; Revised version received and approved: May 27, 2009; Published: May 31, 2009. 